\title{
TINJAUAN KOMPLEMENTER PENGARUH TEORI MARKET-BASED VIEW (MBV) DAN RESOURCE-BASED VIEW (RBV) TERHADAP STRATEGI DAN KINERJA PERUSAHAAN
}

\author{
Boto Simatupang \\ Management Department, School of Business Management, BINUS University \\ Jln. K.H. Syahdan No. 9, Palmerah, Jakarta Barat 11480 \\ bsimatupang@binus.edu
}

\begin{abstract}
The influence of the strategy to company performance is the most widely researched topic until now. Various literatures state that the influence of company performance to strategy does not stand alone, but is affected by a variety of external and internal contingency factors. The discussion in this paper begins with a description of the two major strategic management theories in the theory of MBV and RBV. So both theory of $R B V$ and $M B V$ theory indeed complement each other and have an important role in explaining the influence of strategy to the company performance. This research aims to prove which theory is much more instrumental in explaining the influence of strategy on performance is not important to do, because this is futile efforts .
\end{abstract}

Keywords: market-based view (MBV), resource-based view (RBV), company strategy, company performance

\begin{abstract}
ABSTRAK
Pengaruh strategi terhadap kinerja perusahaan merupakan topik yang paling banyak diteliti hingga kini. Berbagai literatur menyatakan bahwa pengaruh strategi terhadap kinerja perusahaan tidak berdiri sendiri, namun dipengaruhi oleh berbagai faktor kontinjensi eksternal dan internal. Pembahasan dalam makalah ini dimulai dengan uraian dua teori utama dalam manajemen stratejik yaitu teori MBV dan RBV. Jadi kedua teori $R B V$ dan $M B V$ sesungguhnya saling melengkapi dan memiliki peran penting dalam menjelaskan pengaruh strategi terhadap kinerja perusahaan. Penelitian untuk membuktikan teori manakah yang jauh lebih berperan dalam menjelaskan pengaruh strategi terhadap kinerja tidaklah penting untuk dilakukan, karena usaha tersebut akan sia-sia.
\end{abstract}

Kata kunci: market-based view (MBV), resource-based view (RBV), strategi perusahaan, kinerja perusahaan 


\section{PENDAHULUAN}

Pengaruh strategi terhadap kinerja perusahaan merupakan topik yang paling banyak diteliti hingga kini. Berbagai literatur menyatakan bahwa pengaruh strategi terhadap kinerja perusahaan tidak berdiri sendiri, namun dipengaruhi oleh berbagai faktor kontijensi eksternal dan internal. Bahkan secara spesifik DeSarbo, Benedetto, Song, dan Sinha (2005) dan Henderson dan Mitchell (1997) menyatakan bahwa pengaruh strategi terhadap kinerja perusahaan ditentukan oleh lingkungan dan kapabilitas. Pengaruh lingkungan persaingan terhadap strategi dan implikasinya pada kinerja perusahaan merupakan fokus bahasan teori Market Based View (MBV), sedangkan pengaruh kapabilitas terhadap strategi dan implikasinya pada kinerja perusahaan merupakan fokus bahasan teori Resource Based View (RBV). Pembahasan dalam makalah ini dimulai dengan uraian dua teori utama dalam manajemen stratejik yaitu teori MBV dan RBV. Bagian akhir membahas peran komplementer kedua teori tersebut dalam menjelaskan pengaruh strategi terhadap kinerja perusahaan.

\section{PEMBAHASAN}

\section{Teori Market Based View (MBV)}

Teori MBV menyatakan bahwa kinerja perusahaan ditentukan oleh posisi unik perilaku stratejik perusahaan dalam menanggapi persaingan pasar (Hoskisson, Hitt dan Ireland, 2004; Porter, 1980, 1985, 1996). Teori ini menekankan pentingnya peran pasar yang kompetitif sebagai penentu perilaku perusahaan yang kemudian memberikan implikasi pada kinerja perusahaan.

Teori MBV merupakan modifikasi teori Organisasi Industri ke dalam ranah manajemen stratejik (Spanos dan Liokas, 2001). Teori Organisasi Industri sangat dikenal dengan kerangka pemikiran Structure-Conduct-Performance yaitu struktur industri menentukan perilaku industri dan kinerja industri (Bain, 1956; Mason, 1939). Struktur industri dimaksud terdiri dari jumlah pembeli dan penjual, diferensiasi produk, entry barriers, struktur biaya, integrasi vertikal dan diversifikasi (Scherer, 1980). Perilaku dimaksud terdiri dari perilaku harga, strategi produk, advertensi, riset dan inovasi, investasi pabrik dan taktik legal (Scherer, 1980). Modifikasi yang dimaksud di atas adalah (Porter, 1981): (1) Bila teori Organisasi Industri memiliki fokus unit analisis pada level industri, maka teori MBV memiliki fokus unit analisis pada level perusahaan; (2) Bila teori Organisasi Industri memiliki pandangan bahwa struktur industri memiliki peran yang deterministik terhadap perilaku dan kinerja, maka teori MBV menyatakan bahwa lingkungan persaingan tidak sepenuhnya bersifat deterministik dan perusahaan memiliki sejumlah pilihan stratejik (Child, 1972, 1997) dalam merespon lingkungan kompetitif (Porter, 1981).

Modifikasi teori Organisasi Industri ke dalam teori MBV dipelopori oleh Porter (1981) dengan mengajukan Kerangka Lima Kekuatan Porter $(1980,1981,1996)$ yang intinya menyatakan bahwa kinerja perusahaan yang superior tergantung pada posisi unik perusahaan dalam lingkungan kompetitif yang terbentuk dari lima kekuatan persaingan sebagai berikut: kekuatan pembeli, ancaman pesaing baru, kekuatan pemasok, ancaman substitusi dan intensitas persaingan (Porter, 1980, 1996). Posisi unik untuk memperoleh keunggulan daya saing dan kinerja superior hanya dapat diperoleh dengan menerapkan salah satu strategi generik yaitu biaya rendah, keunikan produk dan fokus (Porter, 1980, 1996). Porter (1989) mengungkapkan secara konseptual bahwa kerangka pemikiran yang sama seperti di atas dapat diterapkan pada perusahaan pengembang properti.

Lingkungan kompetitif yang dimaksud oleh Porter (1980, 1985, 1996) serupa dengan lingkungan kerja (task environment) yang dimaksud oleh Dill (1976) dan Dess dan Beard (1984) yaitu elemen lingkungan yang memiliki pengaruh langsung terhadap kelangsungan perusahaan baik sebagai 
sumber informasi maupun sumber daya (Kreiser dan Marino, 2002; Tan dan Litschert, 1994). Kinerja perusahaan yang superior diperoleh sebagai implikasi kesesuaian pilihan stratejik perusahaan (Child, 1972, 1997; Porter, 1980) dalam merespon lingkungan kompetitifnya (Prescott, 1986; Venkatraman dan Prescott, 1990). Berbagai pemikiran teori MBV di atas mengantar pada paradigma riset Environment-Strategy-Performance atau ESP (Luo dan Park, 2001) dalam riset manajemen stratejik.

Posisi unik perusahaan terhadap lingkungan kompetitif tidak terbatas pada strategi generik Porter (1980) saja, namun dapat berupa orientasi stratejik yaitu strategi sebagai kombinasi pola perilaku yang unik (Venkatraman, 1989), seperti yang ditunjukkan oleh penelitian Lukas, Tan dan Hult (2001); Tan dan Litschert (1994); dan Tan dan Tan (2005). Penelitian Lukas et al. (2001) menunjukkan bahwa perusahaan yang memposisikan perilaku proaktif dan berani mengambil resiko dalam lingkungan yang ditandai oleh rendahnya dinamika dan hostilitas lingkungan memberikan pengaruh yang positif yang signifikan terhadap kinerja perusahaan. Penelitian Tan dan Litschert (1994) menunjukkan bahwa dalam lingkungan yang ditandai oleh tingginya dinamika, kompleksitas dan hostilitas lingkungan maka perilaku defensif memberikan pengaruh positif yang signifikan terhadap kinerja perusahaan. Penelitian Tan dan Tan (2005) yang mengulangi penelitian Tan dan Litschert (1994) menunjukkan bahwa dalam lingkungan yang ditandai oleh dinamika, kompleksitas dan hostilitas lingkungan yang lebih rendah dibandingkan dengan penelitian Tan dan Litschert (1994), maka perusahaan bersikap lebih proaktif, inovatif dan berani mengambil resiko; dan ketiga sikap tersebut memberikan pengaruh yang positif terhadap kinerja perusahaan. Berbagai penelitian terdahulu tentang orientasi stratejik tersebut mengindikasikan kesimpulan bahwa kinerja perusahaan ditentukan oleh orientasi stratejik yang berupa kombinasi unik berbagai perilaku stratejik sebagai respon terhadap konteks lingkungan tertentu.

Berbagai literatur manajemen stratejik mengatakan bahwa pengaruh strategi terhadap kinerja perusahaan tidak hanya dipengaruhi oleh lingkungan eksternal saja, namun dipengaruhi juga oleh lingkungan internal (Parnell, 2002, 2006; Parnel et al., 2000). Lingkungan internal dimaksud adalah kapabilitas perusahaan (DeSarbo et al., 2005; Henderson dan Micthell, 1997). Untuk itu, bagian berikut ini menguraikan teori RBV yang menjelaskan peran kapabilitas terhadap strategi dan implikasinya pada kinerja perusahaan.

\section{Teori Resource Based View (RBV)}

Teori RBV mengatakan bahwa keunggulan daya saing dan kinerja perusahaan yang superior bertumpu pada kapabilitas perusahaan yang spesifik (Amit dan Schoemaker, 1993; Barney, 1991; Dierickx dan Cool, 1989; Prahalad dan Hamel, 1990; Mahoney dan Pandian, 1992; Penrose, 1959; Peteraf, 1993; Wernerfelt, 1984). Bahkan Barney (1991) menyatakan bahwa kapabilitas dimaksud haruslah yang bernilai, langka, tidak bisa ditiru dan tidak bisa digantikan.

Sekalipun berbagai peneliti menggunakan berbagai terminologi yang berbeda untuk kapabilitas namun semuanya memiliki pengertian yang mirip satu sama lain yaitu kemampuan yang memberikan keunggulan daya saing dan kinerja superior bagi perusahaan (Lenz, 1980; Stalk, Evans dan Shulman, 1992), seperti disebutkan terminologi berikut ini: (1) Kapabilitas stratejik (DeSarbo et al., 2005; DeSarbo, Benedetto, Jedidi dan Song, 2006; Lenz, 1980; Prahalad, 1983; Stalk et al., 1992); (2) Organizational capabilities (Collis, 1994; O’Regan dan Ghobadian, 2004); (3) Firm capabilities (Di Benedetto dan Song, 2003; (4) Competencies (Hall, 1993); (5) Core competence (Prahalad dan Hamel, 1990); (6) Distinctive competence (Hitt dan Ireland, 1986; Selznick, 1957; Snow dan Hrebiniak, 1980); (7) Core skills (Irvin dan Michaels, 1989); (8) Invisible assets (Itami, 1987); dan (9) Intermediate goods (Amit dan Schoemaker, 1983). Untuk menjaga konsistensi penggunaan terminologi, maka dalam penelitian ini dipergunakan terminologi kapabilitas stratejik. 
Kapabilitas tidak hanya menjadi basis keunggulan daya saing dan kinerja perusahaan yang superior, tetapi juga merupakan basis dalam menentukan strategi perusahaan (Barney, 1991; Collis, 1991; Conner, 1991; Grant, 1991; Lawless, Berg dan Wilsted, 1989). Berbagai penelitian empirik terdahulu menunjukkan bahwa strategi tertentu berbasiskan pada kapabilitas tertentu, dan kesesuaian antara keduanya memberikan pengaruh positif yang signifikan terhadap kinerja perusahaan (Conant, Mokwa dan Varadarajan, 1990; DeSarbo et al., 2006; Di Benedetto dan Song, 2003; Edelman, Brush dan Manolova, 2005; Grant, 2005; Hitt dan Ireland, 1985; Hitt dan Ireland, 1986; Hitt, Ireland dan Palia, 1982; Hitt, Ireland dan Stadter, 1982; Hoskisson et al., 2004; Snow dan Hrebiniak, 1980; Woodside, Sullivan dan Tarppey III, 1999).

\section{Peran Komplementer Teori MBV dan RBV dalam Menjelaskan Pengaruh Strategi terhadap Kinerja Perusahaan}

Teori MBV dan RBV menyatakan bahwa faktor internal dan eksternal mempengaruhi kinerja perusahaan (Hansen dan Wernerfelt, 1989; Hawawini, Subramanian dan Verdin, 2003; Roquebert, Philips dan Wesfall, 1996; Rumelt, 1991; Schamalensee, 1985; Tvorik dan McGivern, 1997). Adapun besarnya peran masing-masing faktor tersebut tergantung kepada: (1) konteks lingkungan persaingan (Makhija, 2003; McGahan dan Porter, 1997; Roquebert et al., 1996); (2) konteks industri (McGahan dan Porter, 1997; Silverman, Nickerson dan Freeman, 1997).

Henderson dan Mitchell (1997) mengatakan bahwa lingkungan dan kapabilitas bersama-sama mempengaruhi strategi dan memberikan implikasi pada kinerja perusahaan, bahkan dikatakan seluruh variabel tersebut sebagai endogenous dan memiliki hubungan resiprokal. Penelitian empirik Huygens, Baden-Fuller, Van Den Bosch dan Volberda (2001); McGahan dan Porter (1997); dan Silverman et al. (1997) mengungkapkan hubungan resiprokal antara lingkungan persaingan dengan kapabilitas. Ketika perusahaan dihadapkan pada persaingan, maka perusahaan selalu berusaha meningkatkan kapabilitasnya agar dapat meningkatkan kinerjanya (Barnett dan Hansen, 1996; Huygens et al., 2001; March, 1991). Bila perusahaan tidak dapat meningkatkan kemampuannya untuk menyesuaikan diri terhadap persaingan, maka perusahaan tersebut tersingkir dari persaingan (Hannan dan Freeman, 1977). Pengaruh resiprokal antara lingkungan dan strategi juga ditunjukkan oleh penelitian Tan dan Litschert (1994) dan Tan dan Tan (2005). Kedua penelitian ini menunjukkan bahwa orientasi stratejik atau strategi sebagai pola perilaku dan ketidakpastian lingkungan bersifat co-evolving (Tan dan Tan, 2005).

Jadi diskusi pada paragraf di atas menyimpulkan bahwa pengaruh strategi terhadap kinerja perusahaan tidak berdiri sendiri namun senantiasa bersifat kontijensi terhadap faktor internal dan eksternal (Ginsberg dan Venkatraman, 1985). Para manajer memiliki pilihan stratejik (Child, 1972, 1997) sebagai respon terhadap pengaruh lingkungan dan kapabilitas. Keunggulan daya saing dan kinerja superior bertumpu pada fit antara kapabilitas, lingkungan dan strategi (Fuchs, Mifflin, Miller dan Whitney, 2000; Lenz, 1981; Levinthal dan Myatt, 1994; Porter, 1996; Schendel, 1997; Tvorik dan McGivern, 1997; White dan Hamermesh, 1981).

\section{SIMPULAN}

Pengaruh lingkungan eksternal terhadap strategi dan implikasinya pada perusahaan merupakan fokus bahasan teori MBV, sedangkan pengaruh kapabilitas terhadap strategi dan implikasinya pada perusahaan merupakan fokus bahasan teori RBV. Jadi kedua teori RBV dan MBV sesungguhnya saling melengkapi dan memiliki peran penting dalam menjelaskan pengaruh strategi terhadap kinerja perusahaan. Penelitian untuk membuktikan teori manakah yang jauh lebih berperan dalam menjelaskan pengaruh strategi terhadap kinerja tidaklah penting untuk dilakukan, karena usaha 
tersebut akan sia-sia (Henderson dan Mitchell, 1997). Namun yang jauh lebih penting untuk dipahami adalah konteks penelitian dimana kedua teori tersebut mampu menjelaskan dengan lebih baik tentang pengaruh strategi terhadap kinerja perusahaan. Seberapa besar peran masing-masing teori tersebut dalam menjelaskan pengaruh strategi terhadap kinerja perusahaan bersifat kontekstual. Namun demikian kedua teori sejalan dalam menyatakan bahwa keselarasan antara faktor eksternal (lingkungan) dan faktor internal (kapabilita) dengan orientasi stratejik memberikan pengaruh positif yang signifikan terhadap kinerja perusahaan.

Penelitian yang mengadopsi kedua teori diatas pada perusahaan di Indonesia relatif terbatas. Oleh karenanya, penulis mengusulkan beberapa penelitian, yaitu: (1) penelitian yang memiliki fokus pada industri tertentu; dan (2) penelitian yang memiliki fokus pada perusahaan pada tahapan start-up, maturity, atau declining.

\section{DAFTAR PUSTAKA}

Amit, R., \& Schoemaker, P. J. (1993). Strategic Assets dan Organizational Rent. Strategic Management Journal, 14, 33-46.

Bain, J. (1956). Barriers to new competition. Cambridge, MA: Harvard University Press.

Barnett, W., \& Hansen, M. (1996). The red queen in organizational evolution. Strategic Management Journal, 17, 139-157.

Barney, J. B. (1991). Firm resources and sustained competitive advantage. Journal of Management, 17, 99-120.

Child, J. (1972). Organizational structure, environment and performance: The role of strategic choice. Sociology, 6: 1-22.

. (1997). Strategic choice in the analysis of action, structure, organizations and environment: Retrospect and prospect. Organization Studies, 18: 43-76.

Collis, D. J. (1991). A resource-based analysis of global competition: The case of the bearings industry. Strategic Management Journal, 12: 49-68.

Collis, D. (1994). Research note: How valuable are organizational capabilities? Strategic Management Journal. 15: 143-152.

Conant, J. S., Mokwa, M. P., \& Varadarajan, P. R. (1990). Strategic types, distinctive marketing competencies and organizational performance: A multiple measures-based study. Strategic Management Journal, 11: 365-383.

Conner, K. R. (1991). A historical comparison of resource-based theory and five schools of thought within industrial organization economics: Do we have a new theory of the firm? Journal of Management, 17: 121-154.

DeSarbo, W. S., Di Benedetto, C. A., Jedidi, K., \& Song, M. (2006). Identifying sources of heterogeneity for empirically deriving strategic types: A constrained finite-mixture structuralequation methodology. Management Science, 52: 909-924. 
DeSarbo, W., Di Benedetto, C. A., Song, M., \& Sinha, I. (2005). Revisiting the Miles and Snow Strategic Framework: Uncovering Interrelationships between Strategic Types, Capabilities, Environmental Uncertainty, and Firm Performance. Strategic Management Journal, 26: 47-74.

Dess, G. G., \& Beard, D. (1984). Dimensions of organizational task environments. Administrative Science Quarterly, 29: 52-73.

Di Benedetto, C.A., \& Song, M. (2003). The relationship between strategic type and firm capabilities in Chinese Firm. International Marketing Review, 20: 514- 533.

Dierickx, I., \& Cool, K. (1989). Asset stock accumulation and sustainability of competitive advantage. Management Science. 35: 1504-1511.

Dill, W. R. (1976). Environment as an influence on managerial autonomy. Administrative Science Quarterly. 2: 409-443.

Edelman, L., Brush, C., \& Manolova, T. 2005. Co-alignment in the resource-performance relationship: strategy as mediator. Journal of Business Venturing. 20: 359-383.

Fuchs, P. H., Mifflin, K. E., Miller, D., \& Whitney, J. O. (2000). Strategic integration: Competing in the age of capabilities. California Management Review, 42: 118-147.

Ginsberg, A., \& Venkatraman, N. (1985). Contingency perspectives of organizational strategy: A critical review of the empirical research. Academy of Management Review, 10: 421-434.

Grant, R. (2005). Contemporary strategy analysis. Malden, MA: Blackwell.

Grant, R. M. (1991). The resource-based theory of competitive advantage: Implications for strategy formulation. California Management Review. Spring: 114-135.

Hall, R. (1993). A framework linking intangible resources and capabilities to sustainable competitive advantage. Strategic Management Journal. 14(8): 607-618.

Hannan, M., \& Freeman, J. (1977). The population ecology of organization. The American Journal of Sociology, 82: 929-964.

Hansen, G., \& Wernerfelt, B. (1989). Determinants of firm performance: the relative importance of economic and organizational factors. Strategic Management Journal. 10: 399-411.

Hawawini, G., Subramanian, V., \& Verdin, P. (2003). Is performance driven by industry or firmspecific factors? A new look at the evidence. Strategic Management Journal. 24 (1): 1-16.

Henderson, R., \& Mitchell, W. (1997). The Interactions of Organizational and Competitive Influences on Strategy and Performance. Strategic Management Journal, 18: 5-14.

Hitt, M. A., \& Ireland, R. D. (1985). Corporate distinctive competence, strategy, industry and performance. Strategic Management Journal. 6: 273-293.

Hitt, M. A., \& Ireland, R. D. (1986). Relationship among corporate level distinctive competencies, diversification strategy, corporate structure and performance. Journal of Management Studies. 23(4): 401-416. 
Hitt, M. A., Ireland, R. D., \& Palia, K. A. (1982). Industrial firms' grand strategy and functional importance: moderating effects of technology and structure. Academy of Management Journal. 25: 265-298.

Hitt, M. A. Ireland, R. D., \& Stadter, G. (1982). Functional importance and company performance: moderating effects of grand strategy and industry type. Strategic Management Journal. 3: 315-330.

Hoskisson, R. E., Hitt, M. A., \& Ireland, R. D. (2004). Competing for advantage. Ohio: Thomson.

Huygens, M., Baden-Fuller, C., Van Den Bosch, F. A. J., \& Volberda, H. W. (2001). Co-evolution of firm capabilities and industry competition: Investigating the music industry, 1877-1997. Organization Studies, 22: 971-1011.

Irvin, R. A., \& Michaels, E. G. (1989). Core skills: Doing the right things right. The McKinsey Quarterly. Summer: 4-19.

Itami, H. (1987). Mobilizing invisible assets. Cambridge, MA: Harvard University Press.

Kreiser, P., \& Marino, L. (2002). Analyzing the historical development of the environmental uncertainty construct. Management Decision, 40: 895.

Lawless, M. W., Bergh, D., \& Wilsted, W. D. (1989). Performance variations among strategic group members: An examination of individual firm capability. Journal of Management. 15(4): 649661.

Lenz, R. T. (1980). Strategic capability: A concept and framework for analysis. Academy of Management Review, 5: 225-234.

Lenz, R. T. (1981). 'Determinants' of organizational performance: an interdisciplinary review. Strategic Management Journal. 2: 131-154.

Levinthal, D., \& Myatt, J. (1994). Co-evolution of capabilities and industry; the evolution of mutual fund processing. Strategic Management Journal. 15: 45-62.

Lukas, B. A., Tan, J. J., \& Hult, G. T. M. (2001). Strategic fit in transitional economies: The case of china's electronics industry. Journal of Management, 27: 409-429.

Luo, Y., \& Park, S. H. (2001). Strategic alignment and performance of market-seeking MNC in China. Strategic Management Journal, 22: 141-155.

Mahoney, J. T., \& Pandian, J. R. (1992). The resource-based view within the conversation of strategic management. Strategic Management Journal. 13:363-380.

Makhija, M. (2003). Comparing the resource-based and market-based views of the firm: Empirical evidence from Czech Privatization. Strategic Management Journal, 24: 433-451.

March, J. G. (1991). Exploration and exploitation in organizational learning. Organization Science. 2(1): 71-87.

Mason, E. S. (1939). Price and production policies of large scale enterprises. The American Economic Review, 29: 61-74. 
McGahan, A. M., \& Porter, M. E. (1997). How much does industry matter really. Strategic Management Journal, 18:15-30.

O’Regan, N., \& Ghobadian, A. (2004). The importance of capabilities for strategic direction and performance. Management Decision, 42: 292-312.

Parnell, J. A. (2002). Competitive strategy research. Journal of Management Research, 2(1): 1-12.

Parnell, J. A. (2006). Generic strategies after two decades: A reconceptualization of competitive strategy. Management Decision, 44: 1139-1154.

Penrose, E. (1959). The growth of the firm. Basil Blackwell. Oxford.

Peteraf, M. A. (1993). The cornerstones of competitive advantage: A resource-based views. Strategic Management Journal. 14(3): 179-191.

Porter, M. (1980). Competitive strategy: Techniques for analyzing industries and competitors. New York: The Free Press.

. (1981). The contributions of industrial organization to strategic management. Academy of Management Review, 6: 604-620.

. (1985). Competitive advantage: Creating and sustaining superior performance. New York: The Free Press.

(1996). On competition. Boston: Harvard Business School.

Prahalad, C. K. (1983). Developing strategic capability: An agenda for top management. Human Resource Management. Fall 22(3): 237-254.

Prahalad, C. K., \& Hamel, G. (1990). The core competence of the corporation. Harvard Business Review. 64: 79-91.

Prescott, J. (1986). Environments as moderators of the relationship between strategy and performance. Academy of Management Journal. 29(2): 329-345.

Roquebert, J., Phillips, R., \& Westfall, P. (1996). Markets vs management: What 'drives' profitability? Strategic Management Journal. 17: 653-664.

Rumelt, R. P. (1991). How much does industry matter? Strategic Management Journal. 12: 167-185.

Schendel, D. (1997). The interactions of organizational and competitive influences on strategy and performance. Strategic Management Journal, 18: 1-3.

Scherer, F. M. (1980). Industrial market structure and economic performance. Chicago: Rand McNally College Publishing.

Silverman, B., Nickerson, J., \& Freeman, J. (1997). Profitability, transactional alignment, and organizational mortality in the US trucking industry. Strategic Management Journal, 18: 3152.

Snow, C. C., \& Hrebiniak, L. G. (1980). Strategy, distinctive competence, and organizational performance. Administrative Science Quarterly, 6: 317-336. 
Spanos, Y. E., \& Lioukas, S. (2001). An examination into the causal logic of rent generation: Contrasting Porter's competitive strategy framework and the resource-based perspective. Strategic Management Journal, 22: 907-934.

Stalk, G., Evans, P., \& Shulman, L. E. (1992). Competing on capabilities: The new rules of corporate strategy. Harvard Business Review, 70: 57-69.

Selznick, P. (1957). Leadership in administration. Harper and Row. New York.

Tan, J., \& Litschert, R. (1994). Environment-strategy relationship and its performance implications: An empirical study of the Chinese electronics industry. Strategic Management Journal, 15: 120.

Tan, J., \& Tan, D. (2005). Environment-strategy co-evolution and co-alignment: A staged model of Chinese SOEs under transition. Strategic Management Journal, 26: 141-157.

Tvorik, S., \& McGivern, M. (1997). Determinants of organizational performance. Management Decision. 35(6): 417-435.

Venkatraman, N. (1989). Strategic orientation of business enterprises: The construct, dimensionality, and measurement. Management Science, 35: 942-962.

Venkatraman, N., \& Prescott, J. E. (1990). Environment-strategy coalignment: An empirical test of its performance implication. Strategic Management Journal, 11: 1-23.

Wernerfelt, B. (1984). A resource-based view of the firm. Strategic Management Journal. 5: 171-180.

White, R., \& Hamermesh, R. (1981). Toward a model of business unit performance: An integrative approach. Academy of Management. 6(2): 213-223.

Woodside, A. G., Sullivan, D. P., \& Trappey III, R. J. (1999). Assessing relationship among strategic types, distinctive marketing competencies, and organizational performance. Journal of Business Research. 45: 135-146. 